\title{
A Convenient Fluorescence-Based Assay for the Detection of Sucrose Transport and the Introduction of a Sucrose Transporter from Potato into Clostridium Strains
}

\author{
Zhikai Zhang ${ }^{1,+}$, Lihua Lin ${ }^{2,+}$, Hongchi Tang ${ }^{2}$, Shaowei Zeng ${ }^{1}$, Yuan Guo ${ }^{2}$, Yutuo Wei ${ }^{1, *}$, \\ Ribo Huang ${ }^{1}$, Hao Pang ${ }^{2}$ and Liqin Du ${ }^{1, *}$ \\ 1 State Key Laboratory for Conservation and Utilization of Subtropical Agro-bioresources, Guangxi Research \\ Center for Microbial and Enzymatic Technology, College of Life Science and Technology, Guangxi University, \\ Daxue Road No. 100, Nanning 530005, China; zhikaizhang10@163.com (Z.Z.); \\ SKzengshaowei@163.com (S.Z.); guruace@163.com (R.H.) \\ 2 National Engineering Research Center for Non-Food Biorefinery, State Key Laboratory of Non-Food Biomass \\ and Enzyme Technology, Guangxi Key Laboratory of Bio-refinery, Guangxi Academy of Sciences, Daling \\ Road No. 98, Nanning 530007, China; linlihua_8@126.com (L.L.); thc024003@163.com (H.T.); \\ 1201guoyuan@163.com (Y.G.); panghouse@126.com (H.P.) \\ * Correspondence: weiyutuo@gxu.edu.cn (Y.W.); duliqin@gxu.edu.cn (L.D.); Tel.: +86-771-3235707 (Y.W.); \\ +86-771-3235706 (L.D.) \\ + These authors contributed equally to this work.
}

Academic Editor: Haiying Liu

Received: 24 July 2019; Accepted: 24 September 2019; Published: 26 September 2019

\begin{abstract}
A convenient and effective sucrose transport assay for Clostridium strains is needed. Traditional methods, such as ${ }^{14} \mathrm{C}$-sucrose isotope labelling, use radioactive materials and are not convenient for many laboratories. Here, a sucrose transporter from potato was introduced into Clostridium, and a fluorescence assay based on esculin was used for the analysis of sucrose transport in Clostridium strains. This showed that the heterologously expressed potato sucrose transporter is functional in Clostridium. Recombinant engineering of high-level sucrose transport would aid sucrose fermentation in Clostridium strains. The assay described herein provides an important technological platform for studying sucrose transporter function following heterologous expression in Clostridium.
\end{abstract}

Keywords: sucrose transporter; esculin; fluorescence assay; Clostridium

\section{Introduction}

It is of current interest to determine methods to efficiently use sugars (such as cellulose, xylose, and sucrose) from non-food biomass feedstocks as the carbon source for microbial fermentation [1-3], as this is a key factor restricting the conversion of non-food biomass to biofuel and high value-added chemicals. Sugar transport systems may play an important role in this process $[4,5]$. Genetic engineering at the transporter level is an evolving field; however, there have been few studies focused on improving the yield of biofuels. In contrast, much research has been performed on yeast [6-8], and the latest reports show that engineering of the yeast sugar transport system enhances fermentation [9-11]. Hyperthermophiles are interesting bacteria that encode many ATP binding cassette type (ABC-type) transporters and recently these transporters have been used to increase hydrogen production. The maltose transporter was genetically characterized in Thermotoga maritima, and genetic engineering of this transporter improved the fermentation efficiency of this bacterium $[12,13]$. Introduction of a sucrose permease from Escherichia coli and a sucrose phosphorylase from Streptococcus 
mutans into Bacillus subtilis resulted in a recombinant strain that showed remarkable enhancement of 2,3-butanediol production compared with the control strain [14]. Overexpression of an endogenous sucrose utilization system, the phosphoenolpyruvate-phosphotransferase system (PEP-PTS) transport protein for sucrose and the related sucrose hydrolase enzymes elevated sucrose consumption and enhanced acetone-butanol-ethanol (ABE) production in Clostridium saccharoperbutylacetonicum N1-4 [15].

Sucrose is the most abundant disaccharide in the environment and an important feedstock for the fermentation industry. In bacteria, there are two pathways to transport sucrose: the phosphoenolpyruvate-phosphotransferase system, which results in the accumulation of sucrose-6-phosphate, and the sucrose permease transport system, which transports unmodified sucrose into the cell. In plants, sucrose transporters (SUTs) operate by the cellular transport of proton-coupled sucrose [16-19]. Type I and II SUTs are localized in the plasma membrane, while type III SUTs are localized in the vacuole membrane [17,19]. Several different methods have been employed to detect the activity of SUTs. ${ }^{14} \mathrm{C}$-sucrose isotope labelling was the first method reported for analyzing sucrose uptake and transport in plants [16]. SUTs from plants were cloned and heterologously expressed in yeast, and sucrose uptake was analyzed using ${ }^{14} \mathrm{C}$-sucrose isotope labelling methods [6], which indicated that yeast was an ideal model in which to study the function of SUTs.

More recently, to rapidly and easily detect sucrose transport activity in yeast, a novel method was developed based on the ability of type I SUTs to transport esculin (6,7-dihydroxycoumarin 6-glucoside, 7-hydroxy-6-[(2S,3R,4S,5S,6R)-3,4,5-trihydroxy-6-(hydroxymethyl)oxan-2-yl]oxychromen-2-one) [16]. Esculin is a structural analogue of sucrose with strong fluorescence (excitation $367 \mathrm{~nm}$, emission 454 $\mathrm{nm}$ ), and the fluorescence positively correlates with the amount of esculin taken up into the cells. Compared with radioactive carbon, the use of esculin is safer and readily available in most labs.

The sucrose transporter StSUT1 from potato (Solanum tuberosum) was expressed in Saccharomyces cerevisiae and was found to be a type I SUT [20]. Butanol is a renewable biofuel that can be produced by fermentation in Clostridium [21,22], but the ability of Clostridium to use sucrose is low [23,24]. Recombinant engineering of Clostridium to achieve high levels of sucrose transport would aid sucrose consumption in Clostridium to produce butanol [15]. In this work, we show that heterologously expressed StSUT1 was functional in Clostridium. beijerinckii and Clostridium. acetobutylicum, and transport of sucrose through this transporter was confirmed by an esculin fluorescence-based method.

\section{Results}

\subsection{Heterologous Expression of the StSUT1 Gene in C. beijerinckii and C. acetobutylicum}

The type I sucrose transporter StSUT1 from potato was overexpressed in C. beijerinckii 8052 (designated strain CB8054) and C. acetobutylicum 792 (designated strain CA794). The gene expression level of StSUT1 was measured by real-time quantitative PCR analysis (qRT-PCR). The results suggested that the StSUT1 gene was effectively expressed in both Clostridium strains, whereas the StSUT1 gene transcript was not detected in the control strains (designated strains CA793 and CB8053) (Figure 1). The relative expression level of StSUT1 in strain CB8054 was significantly higher than that in strain CA794. A $t$-test was applied for difference comparison among the measured data and the $\mathrm{P}$ value was found to be 0.012 . These results indicated that StSUT1 was more effectively expressed in C. beijerinckii compared with $C$. acetobutylicum, likely enhancing the use of sucrose by C. beijerinckii. 


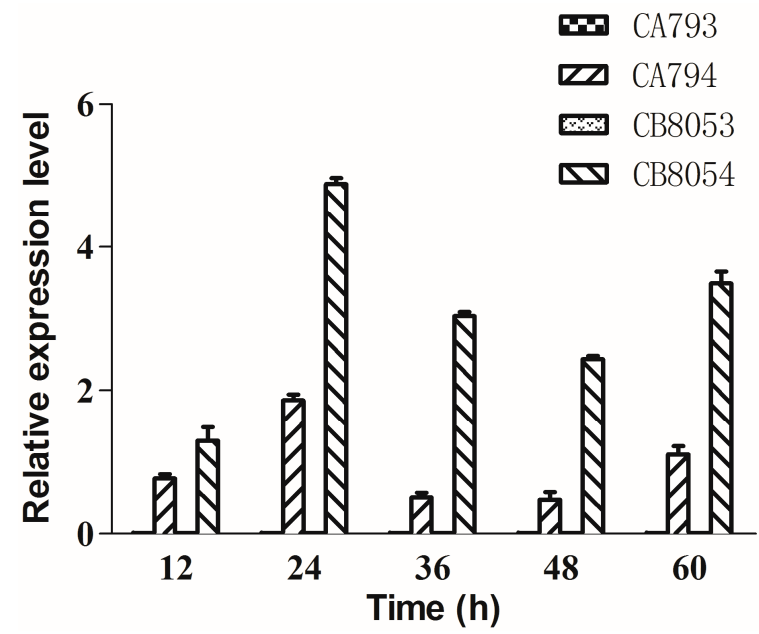

Figure 1. The expression of StSUT1 analyzed by quantitative real time polymerase chain reaction. Cells were collected at $12,24,36,48$, and $60 \mathrm{~h}$. Three independent biological replicates were performed for each gene. The data represent the means of three separate experiments \pm standard deviation. The control strains CA793 and CB8053 did not express StSUT1.

\subsection{Determination of the Activity of the Sucrose Transporter StSUT1 by a Fluorescence-Based Assay}

Strains CB8053, CB8054, CA793, and CA794 were incubated with $1 \mathrm{mM}$ esculin at $\mathrm{pH}$ 4.5, 5.0, $5.5,6.0$, and 6.5 for $2 \mathrm{~h}$. The strains containing StSUT1 emitted higher fluorescence than the vector controls except at pH 6.5 (Figure 2A). At pH 6.5, strain CB8054 showed the same fluorescence value as the control strain, indicating that the recombinant transport system did not work at this $\mathrm{pH}$. At $\mathrm{pH}$ 5.0, strain CB8054 showed the highest fluorescence emission $(61,750 \pm 5,411)$ among all the tested $\mathrm{pH}$ conditions, and the fluorescence sharply decreased to $20,479 \pm 6,674$ when the $\mathrm{pH}$ was decreased to 4.5 . Similarly, the fluorescence value for strain CA794 was highest at pH 5.0.

Strains were incubated with different concentrations of esculin. When incubated with $0.1,0.5,1.0$, 1.5 and $2.0 \mathrm{mM}$ esculin, the fluorescence generally increased with the esculin concentration (Figure 2B). For $C$. acetobutylicum at $0.1 \mathrm{mM}$ esculin, there was an obvious fluorescence signal compared with the control strain; the relative fluorescence value was 19,069 \pm 744 compared with 2,792 \pm 688 for the control. The fluorescence increased up to $1.5 \mathrm{mM}$ esculin. In C. beijerinckii, at low esculin concentration, the transport of esculin was limited; thus, the fluorescence value was only $6,335 \pm 755$ at $0.1 \mathrm{mM}$ esculin. However, when the concentration of esculin was increased to $1.5 \mathrm{mM}$, the fluorescence was $27,851 \pm 5,099$, and at $2.0 \mathrm{mM}$ esculin it reached 69,663 \pm 0 . A higher concentration of esculin was not tested because of its low solubility in water.

Strains were also incubated with esculin for different times. When strains CB8053, CB8054, CA793 and CA794 were incubated for 1 to $5 \mathrm{~h}$ in $1 \mathrm{mM}$ esculin at $\mathrm{pH}$ 5.0, high fluorescence values were obtained that differed slightly among the strains (Figure 2C). After incubation for $1 \mathrm{~h}$, strains CB8054 and CA794 showed an obvious difference in fluorescence compared with their respective control strains.

Taken together, these results show that the Clostridium strains express the type I SUT from potato, the activity of which can be rapidly detected using a fluorescence-based assay. 

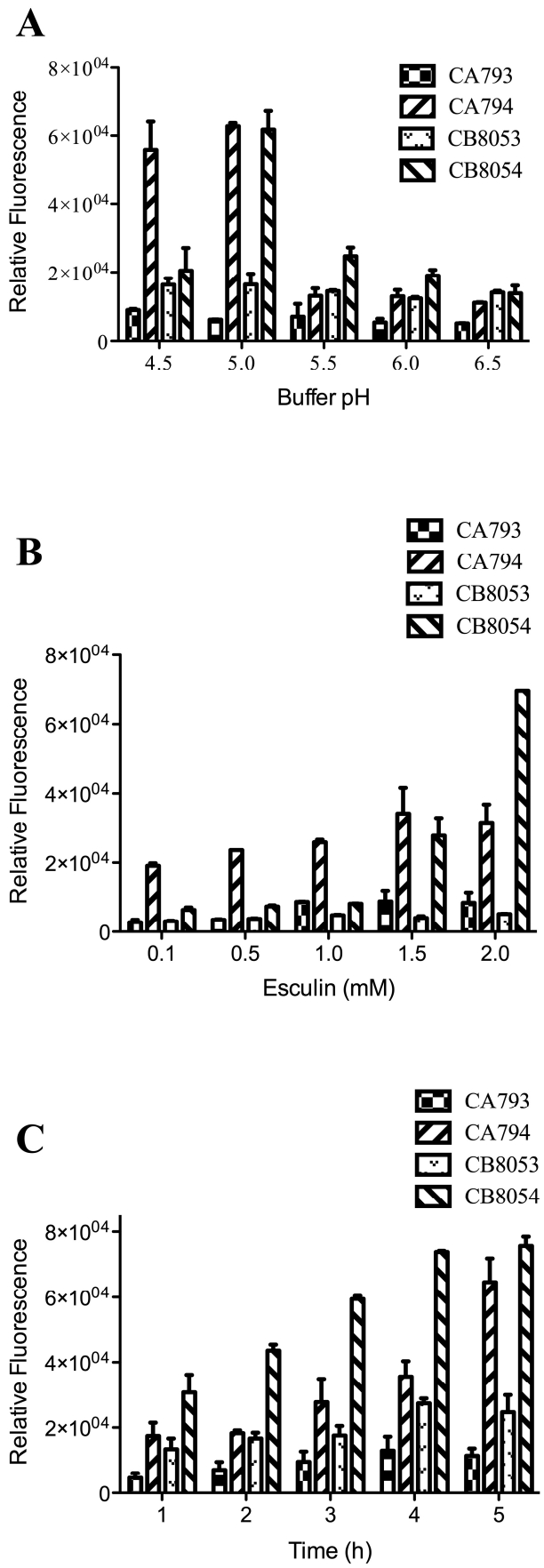

Figure 2. Analysis of esculin uptake in Clostridium strains under different conditions. (A) Effect of $\mathrm{pH}$ on esculin uptake. Clostridium cells were incubated with $1.0 \mathrm{mM}$ esculin for $2 \mathrm{~h}$ at different $\mathrm{pH}$ values. (B) Effect of the concentration of esculin on esculin uptake. Clostridium cells were incubated with different concentrations of esculin at $\mathrm{pH} 5.0$ for $2 \mathrm{~h}$. (C) Effect of incubation time on esculin uptake. Clostridium cells were incubated with $1.0 \mathrm{mM}$ esculin at $\mathrm{pH} 5.0$ for the indicated times. The data represent the mean of three separate experiments \pm standard deviation.

\subsection{Sucrose Competition Effect on the Transport System}

Strains were incubated with $1 \mathrm{mM}$ esculin and different concentrations of sucrose. Sucrose showed an obvious inhibitory effect on esculin transport in strains CA794 and CB8054, but not in the control stains CA793 and CB8053 (Figure 3). Thus, sucrose competed with esculin for the StSUT1 transporter 
in strains CA794 and CB8054, indicating that sucrose and esculin use the same transport system in strains CA794 and CB8054.

A
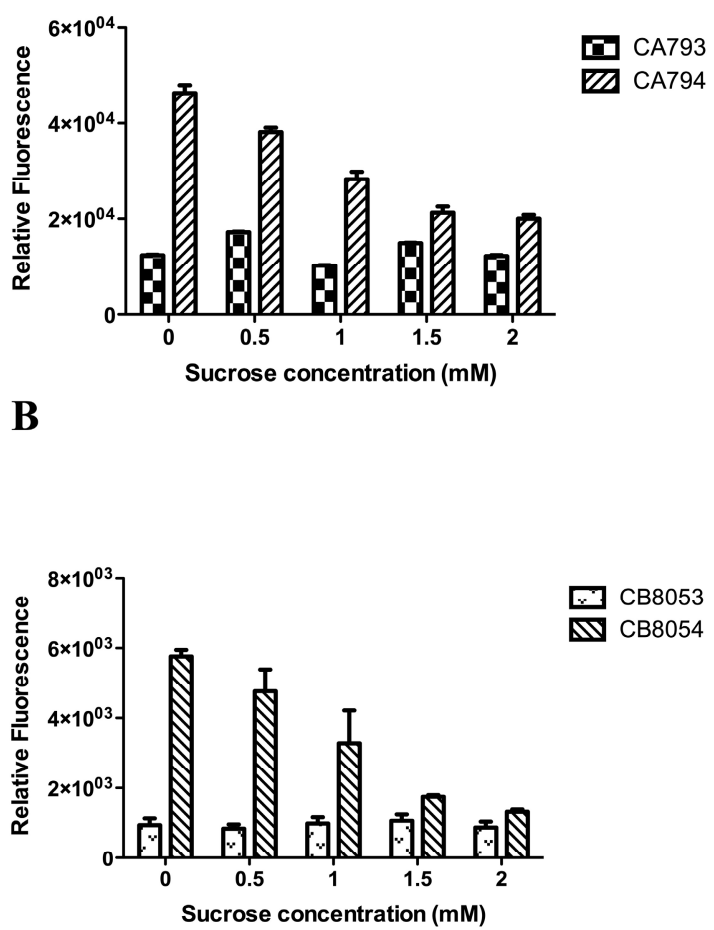

Figure 3. The competition effect of sucrose on esculin transport. Clostridium cells were incubated with $1.0 \mathrm{mM}$ esculin for $2 \mathrm{~h}$ at $\mathrm{pH}$ 5.0. The data represent the mean of three separate experiments \pm standard deviation. (A) Effect of sucrose on esculin uptake in Clostridium acetobutylicum strains. (B) Effect of sucrose on esculin uptake in Clostridium beijerinckii strains.

\section{Discussion}

Renewable sugar, cellulose, and starch biomass are important substrates in industrial ABE fermentation. Sucrose is a cheap and ideal feedstock for ABE fermentation [15]. In C. beijerinckii 8052 and C. acetobutylicum DSM 792, ${ }^{14} \mathrm{C}$-sucrose isotope labelling was employed to demonstrate that sucrose transport occurs via a PEP-PTS mechanism [23,25-27]. In C. beijerinckii, both glucose and sucrose were initially metabolized at the same rate indicating that glucose regulates sucrose use at some level, but does not directly inhibit sucrose uptake [27]. In C. acetobutylicum, sucrose was needed to induce the expression of the PEP-PTS system; however, induction was prevented by the presence of glucose in the culture medium because glucose regulates the PTS gene system, which affected sucrose metabolism [23]. Although the PEP-PTS sucrose uptake system is conserved in both C. beijerinckii and C. acetobutylicum, the organization and regulatory elements of the operons for sucrose metabolism show considerable differences $[23,28]$.

From our results, it is evident that the type I sucrose transporter StSUT1 from potato showed high esculin transfer ability in both C. beijerinckii and C. acetobutylicum strains (Figures 2 and 3). Esculin, a structural analogue of sucrose, is a highly fluorescent molecule. Fluorescence is a type of photoluminescence that is the result of a molecule absorbing light at a specific wavelength and emitting light at a longer wavelength. For esculin, the absorbed light occurs at $367 \mathrm{~nm}$ and the emitted light occurs at $454 \mathrm{~nm}$; the fluorescence positively correlates with the amount of esculin taken up into cells [20]. Thus, it is possible to measure the transport of esculin by a transport system. Moreover, it 
was found that esculin was transported at a rate similar to the transport of sucrose. Therefore, esculin was used as a tool to characterize the sucrose transport activity of the SUT1 transporter from potato when expressed in Clostridium strains [29].

Finding new metabolic pathways to increase sucrose consumption by Clostridium is one way to use this inexpensive and desirable substrate for ABE fermentation. Recently, Zhang et al. enhanced endogenous and introduced heterologous sucrose utilization pathways into C. saccharoperbutylacetonicum [15]. In their work, overexpression of the endogenous sucrose pathway increased sucrose consumption and $\mathrm{ABE}$ production. However, they failed to find heterologous sucrose utilization pathways that could compete with the native sucrose utilization pathways in the host strain. $\mathrm{H}^{+}$-coupled sucrose transporters from plants are considered to be the most efficient sucrose transport system [19,30,31]. StSUT1 from potato is an $\mathrm{H}^{+}$-coupled sucrose transporter and was able to transport esculin into Clostridium cells, and sucrose competition experiments showed that sucrose competed with esculin for transport in recombinant strains CA794 and CB8054 (Figure 3). The sucrose transporter StSUT1 was confirmed to actively uptake sucrose at acidic $\mathrm{pH}$ because it operates by a proton-coupled mechanism [30,31]. Environmental $\mathrm{pH}$ has been reported to be an important factor in the growth and fermentation of Clostridium [32,33]. In previous studies, it was demonstrated that $\mathrm{pH}$ values ranging from 5.5 to 6.0 were optimal for $\mathrm{ABE}$ fermentation $[33,34]$. However, for esculin uptake in the present study, the optimal pH was 5.0 (Figure 3A). At low $\mathrm{pH}$, the sucrose transporter StSUT1 showed high activity, but this is not the best condition for growth and fermentation of Clostridium. Thus, further studies are needed to optimize conditions for the recombinant sucrose uptake system with simultaneous growth and fermentation of Clostridium.

In summary, our findings provide an important technological platform for studying sucrose transporter function by heterologous expression in Clostridium.

\section{Materials and Methods}

\subsection{Bacterial Strains and Plasmids}

Two Clostridium strains were used in this study. The characteristics of these strains, C. beijerinckii NCIMB 8052 [35] and C. acetobutylicum DSM 792 (ATCC 824) [36], have been described in previous reports. Escherichia coli JM109 was used as the cloning host and was purchased from Invitrogen (Carlsbad, CA, USA). Plasmid pAN1 was used for methylating target plasmids [37] and plasmid pSOS95 was used as the expression vector in Clostridium strains [38]. The StSUT1 open reading frame was cloned from plasmid pDR196-StSUT1, which was kindly gifted by Prof. John M. Ward [20].

\subsection{Media and Culture Conditions}

Clostridium strains and E. coli were stored as frozen cultures at $-80^{\circ} \mathrm{C}$. E. coli was cultured at $37^{\circ} \mathrm{C}$ in Luria-Bertani medium supplemented with $50 \mu \mathrm{g} / \mathrm{mL}$ ampicillin or $25 \mu \mathrm{g} / \mathrm{mL}$ chloramphenicol. $C$. beijerinckii NCIMB 8052 and C. acetobutylicum DSM 792 were cultured in Tryptone-yeast extract-acetate (TYA) medium (glucose $40 \mathrm{~g} / \mathrm{L}$, yeast extract $2 \mathrm{~g} / \mathrm{L}$, tryptone $6 \mathrm{~g} / \mathrm{L}$, beef extract $2 \mathrm{~g} / \mathrm{L}, \mathrm{NH}_{4} \mathrm{Ac} 3 \mathrm{~g} / \mathrm{L}$, $\mathrm{K}_{2} \mathrm{HPO}_{4} 0.5 \mathrm{~g} / \mathrm{L}, \mathrm{MgSO}_{4} 0.2 \mathrm{~g} / \mathrm{L}$, and $\mathrm{FeSO}_{4} \cdot 7 \mathrm{H}_{2} \mathrm{O} 0.01 \mathrm{~g} / \mathrm{L}$ ) and Clostridial growth medium (CGM) medium (glucose $50 \mathrm{~g} / \mathrm{L}$, yeast extract $10 \mathrm{~g} / \mathrm{L}$, aspartic amide $2 \mathrm{~g} / \mathrm{L}$, $\left(\mathrm{NH}_{4}\right)_{2} \mathrm{SO}_{4} 2 \mathrm{~g} / \mathrm{L}_{,} \mathrm{KH}_{2} \mathrm{PO}_{4} 0.75 \mathrm{~g} / \mathrm{L}$, $\mathrm{K}_{2} \mathrm{HPO}_{4} 0.75 \mathrm{~g} / \mathrm{L}, \mathrm{MgSO}_{4} 0.4 \mathrm{~g} / \mathrm{L}, \mathrm{FeSO}_{4} 0.01 \mathrm{~g} / \mathrm{L}, \mathrm{MnSO}_{4} 0.01 \mathrm{~g} / \mathrm{L}$, and $\mathrm{NaCl} 1 \mathrm{~g} / \mathrm{L}$ ), respectively. These media were supplemented with $25 \mu \mathrm{g} / \mathrm{mL}$ erythromycin and Clostridium strains were grown at $37^{\circ} \mathrm{C}$ in an anaerobic incubator.

\subsection{Strain Construction}

The sucrose transporter gene StSUT1 from potato was first cloned into Clostridium expression vector pSOS95. The complete open reading frame of StSUT1 was obtained by PCR from pDR196-StSUT1 using primers SUT-F: 5' -AAAGGAGGGATTAAAATGGAGAATGGTACAAAAAGAGAAGG-3' and SUT-R: 5'-TAACTCTTATTTTTATTATTTAATGGAAAGCCCCATGGCGAC-3'. Linear pSOS95 was amplified by PCR from vector pSOS95 DNA using primers pSOS95-F: 5'-TAAAAATAAGAGTTACCTTAAA 
TGGTAACT-3' and pSOS95-R: 5'-TTTAATCCCTCCTTTTAAATTCTGGATCCT-3'. Using an in-fusion cloning system (TaKaRa Bio, Dalian, China), StSUT1 was fused to plasmid pSOS95, and the resulting recombinant expression plasmid was designated pSOS95-StSUT1. Plasmids pSOS95 and pSOS95-StSUT1 were introduced into E. coli JM109-pAN for methylation to avoid rejection by Clostridium, and then methylated plasmids were extracted from strain M109-pAN1 for transformation into C. beijerinckii NCIMB 8052 and C. acetobutylicum DSM 792. Plasmids were introduced into Clostridium strains using electrotransformation technology [39]. The recombinant strains of Clostridium were designated CB8053 (C. beijerinckii 8052/pSOS95), CB8054 (C. beijerinckii 8052/pSOS95-StSUT1), CA793 (C. acetobutylicum 792/pSOS95) and CA794 (C. acetobutylicum 792/pSOS95-StSUT1).

\subsection{Real-Time Quantitative PCR Analysis}

Total RNA was extracted from Clostridium cells using the MiniBEST Universal RNA Extraction Kit (TaKaRa). Reverse transcription was performed using PrimeScript ${ }^{\mathrm{TM}}$ RT Master Mix (Perfect Real Time; TaKaRa). The qRT-PCR primers qSUT-F 5'-CCTTGGTCACGCCTCCGGT-3' and qSUT-R 5'-GCATTTGCTGTTCTCATCC-3' were used for the amplification of StSUT, and qRT-PCR primers 16srRNA-F 5'-GCTCGTGTCGTGAGATGTT-3' and 16srRNA-R 5'-TGTAGCCCAGGTCATAAGG-3' were used for the amplification of $16 S$ rRNA. RT-qPCR was performed with TB Green ${ }^{\mathrm{TM}}$ Premix Ex

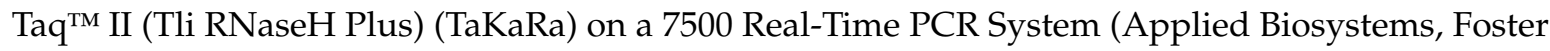
City, CA, USA). The $2^{-\Delta \Delta}$ Ct method was used to detect relative gene expression levels, and $16 S$ rRNA was used as the reference gene. Three technical replicates were tested for every sample, and the data represent the mean of three separate experiments \pm standard deviation. A t-test was performed to analyze the relative gene expression levels between CA794 and CB8054 using GraphPad Prism 5 (GraphPad Software Inc., San Diego, CA, USA).

\subsection{Transport Assays}

Clostridium strains used in this study were cultured in TYA or CGM medium for $12 \mathrm{~h}$. Then, 1 $\mathrm{mL}$ of bacterial suspension was collected and centrifuged at $1,200 \times g$ for $5 \mathrm{~min}$ at room temperature. The bacterial pellet was then washed twice with hydrogen disodium phosphate solution ( $25 \mathrm{mM})$ at the appropriate $\mathrm{pH}$, and the cells were resuspended in $200 \mu \mathrm{L}$ of the same buffer containing esculin. The cells were incubated for $2 \mathrm{~h}$ at $37^{\circ} \mathrm{C}$ in an anaerobic incubator. Then the bacteria were harvested and washed as described above and finally resuspended in $1 \mathrm{~mL}$ of hydrogen disodium phosphate solution $(25 \mathrm{mM})$ at the appropriate $\mathrm{pH}$. The bacterial solution was added to a 96-well microtiter plate. Fluorescence was measured using a black enzyme marker plate at $367 \mathrm{~nm}$ excitation and 454 nm emission with a Sunrise microplate reader (Tecan Group Ltd., Mannedorf, Switzerland), and the optical density of $600 \mathrm{~nm}\left(\mathrm{OD}_{600}\right)$ value was measured using a colorless, transparent enzyme marker plate. The relative fluorescence value was expressed as the fluorescence value per OD unit. Three technical replicates were tested for every sample, and the data represent the means of three separate experiments \pm standard deviation.

Author Contributions: Conceptualization, H.P. and L.D.; investigation, Z.Z., L.L., H.T.; resources, S.Z., Y.G.; writing—original draft preparation, Z.Z.; writing—review and editing, H.P., R.H. and L.D.; project administration, Y.W.; funding acquisition, H.P. and L.D.

Funding: This research was funded by Natural Science Foundation of China $(21566003,21366007)$, the Natural Science Foundation of Guangxi (2014GXNSFAA118078, 2015GXNSFBA139084, 2018GXNSFAA138103), and the Innovation Project of Guangxi Graduate Education (YCBZ2014020).

Acknowledgments: The authors are grateful to John M. Ward for the gift of the StSUT1 gene. We thank Renee Mosi, from Liwen Bianji, Edanz Editing China (www.liwenbianji.cn/ac), for editing the English text of a draft of this manuscript.

Conflicts of Interest: The authors declare no conflict of interest. 


\section{References}

1. Lee, S.H.; Yun, E.J.; Kim, J.; Lee, S.J.; Um, Y.; Kim, K.H. Biomass, strain engineering, and fermentation processes for butanol production by solventogenic clostridia. Appl. Microbiol. Biotechnol. 2016, 100, 8255-8271. [CrossRef] [PubMed]

2. Wackett, L.P. Biomass to fuels via microbial transformations. Curr. Opin. Chem. Biol. 2008, 12, $187-193$. [CrossRef] [PubMed]

3. Qi, X.; Zha, J.; Liu, G.G.; Zhang, W.; Li, B.Z.; Yuan, Y.J. Heterologous xylose isomerase pathway and evolutionary engineering improve xylose utilization in Saccharomyces cerevisiae. Front. Microbiol. 2015, 6, 1165-1176. [CrossRef] [PubMed]

4. Ren, C.; Chen, T.; Zhang, J.; Liang, L.; Lin, Z. An evolved xylose transporter from Zymomonas mobilis enhances sugar transport in Escherichia coli. Microb. Cell Factories 2009, 8, 1-9. [CrossRef] [PubMed]

5. Meadow, N.D.; Rosenberg, J.M.; Pinkert, H.M.; Roseman, S. Sugar transport by the bacterial phosphotransferase system. Evidence that crr is the structural gene for the Salmonella typhimurium glucose-specific phosphocarrier protein IIIGlc. J. Biol. Chem. 1982, 257, 14538-14542. [PubMed]

6. Riesmeier, J.W.; Willmitzer, L.; Frommer, W.B. Isolation and characterization of a sucrose carrier cDNA from spinach by functional expression in yeast. EMBO J. 1992, 11, 4705-4713. [CrossRef] [PubMed]

7. Young, E.; Poucher, A.; Comer, A.; Bailey, A.; Alper, H. Functional survey for heterologous sugar transport proteins, using Saccharomyces cerevisiae as a host. Appl. Environ. Microb. 2011, 77, 3311-3319. [CrossRef]

8. Sauer, N.; Stadler, R. A sink-specific H+/monosaccharide co-transporter from Nicotiana tabacum: Cloning and heterologous expression in baker's yeast. Plant. J. 2010, 4, 601-610. [CrossRef]

9. Lv, H.; Li, J.; Wu, Y.; Garyali, S.; Wang, Y. Transporter and its engineering for secondary metabolites. Appl. Microbiol. Biotechnol. 2016, 100, 6119-6130. [CrossRef] [PubMed]

10. Oh, E.J.; Kwak, S.; Kim, H.; Jin, Y.S. Transporter engineering for cellobiose fermentation under lower $\mathrm{pH}$ conditions by engineered Saccharomyces cerevisiae. Bioresour. Technol. 2017, 245, 1469-1475. [CrossRef]

11. Marques, W.L.; Mans, R.; Henderson, R.K.; Marella, E.R.; Horst, J.T.; Hulster, E.D.; Poolman, B.; Daran, J.; Pronk, J.T.; Gombert, A.K.; et al. Combined engineering of disaccharide transport and phosphorolysis for enhanced ATP yield from sucrose fermentation in Saccharomyces cerevisiae. Metab. Eng. 2018, 45, 121-133. [CrossRef] [PubMed]

12. Singh, R.; White, D.; Blum, P. Identification of the ATPase subunit of the primary maltose transporter in the hyperthermophilic anaerobe Thermotoga maritima. Appl. Environ. Microbiol. 2017, 83, e00930-17. [CrossRef] [PubMed]

13. Singh, R.; White, D.; Demirel, Y.; Kelly, R.; Noll, K.; Blum, P. Uncoupling fermentative synthesis of molecular hydrogen from biomass formation in Thermotoga maritima. Appl. Environ. Microbiol. 2018, 84, e0998-18. [CrossRef] [PubMed]

14. Feng, J.; Gu, Y.; Yan, P.; Song, C.; Wang, Y. Recruiting energy-conserving sucrose utilization pathways for enhanced 2,3-butanediol production in Bacillus subtilis. ACS Sustain. Chem. Eng. 2017, 5, 11221-11225. [CrossRef]

15. Zhang, J.; Wang, P.; Wang, X.; Feng, J.; Sandhu, H.S.; Wang, Y. Enhancement of sucrose metabolism in Clostridium saccharoperbutylacetonicum N1-4 through metabolic engineering for improved acetone-butanol-ethanol (ABE) fermentation. Bioresour. Technol. 2018, 270, 430-438. [CrossRef] [PubMed]

16. Sovonick, S.A.; Geiger, D.R.; Fellows, R.J. Evidence for active phloem loading in the minor veins of sugar beet. Plant. Physiol. 1974, 54, 886-891. [CrossRef]

17. Schulz, A.; Beyhl, D.; Marten, I.; Wormit, A.; Neuhaus, E.; Poschet, G.; Büttner, M.; Schneider, S.; Sauer, N.; Hedrich, R. Proton-driven sucrose symport and antiport are provided by the vacuolar transporters SUC4 and TMT1/2. Plant. J. 2011, 68, 129-136. [CrossRef] [PubMed]

18. Bush, D.R. Proton-coupled sucrose transport in plasmalemma vesicles isolated from sugar beet (Beta vulgaris L. cv Great Western) leaves. Plant. Physiol. 1989, 89, 1318-1323. [CrossRef]

19. Reinders, A.; Sivitz, A.B.; Ward, J.M. Evolution of plant sucrose uptake transporters. Front. Plant. Sci. 2012, 3, 22-33. [CrossRef]

20. Gora, P.J.; Reinders, A.; Ward, J.M. A novel fluorescent assay for sucrose transporters. Plant. Methods 2012, 8, 13-18. [CrossRef] 
21. Ndaba, B.; Chiyanzu, I.; Marx, S. N-Butanol derived from biochemical and chemical routes: A review. Biotechnol. Rep. 2015, 8, 1-9. [CrossRef] [PubMed]

22. Dusséaux, S.; Croux, C.; Soucaille, P.; Meynial-Salles, I. Metabolic engineering of Clostridium acetobutylicum ATCC 824 for the high-yield production of a biofuel composed of an isopropanol/butanol/ethanol mixture. Metab.Eng. 2013, 18, 1-8. [CrossRef] [PubMed]

23. Tangney, M.; Mitchell, W.J. Analysis of a catabolic operon for sucrose transport and metabolism in Clostridium acetobutylicum ATCC 824. J. Mol. Microbiol. Biotechnol. 2000, 2, 71-80. [PubMed]

24. Yu, Y.; Tangney, M.; Aass, H.C.; Mitchell, W.J. Analysis of the mechanism and regulation of lactose transport and metabolism in Clostridium acetobutylicum ATCC 824. Appl. Environ. Microb. 2007, 73, 1842-1850. [CrossRef] [PubMed]

25. Mitchell, W.J. Carbohydrate uptake and utilization by Clostridium beijerinckii NCIMB 8052. Anaerobe 1996, 2, 379-384. [CrossRef]

26. Mitchell, W.J.; Albasheri, K.A.; Yazdanian, M. Factors affecting utilization of carbohydrates by Clostridia. FEMS Microbiol. Rev. 1995, 17, 317-329. [CrossRef]

27. Tangney, M.; Rousse, C.; Yazdanian, M.; Mitchell, W.J. Note: Sucrose transport and metabolism in Clostridium beijerinckii NCIMB 8052. J. Appl. Microbiol. 1998, 84, 914-919. [CrossRef] [PubMed]

28. Reid, S.J.; Rafudeen, M.S.; Leat, N.G. The genes controlling sucrose utilization in Clostridium beijerinckii NCIMB 8052 constitute an operon. Microbiology 1999, 145, 1461-1472. [CrossRef]

29. Rottmann, T.M.; Fritz, C.; Lauter, A.; Schneider, S.; Fischer, C.; Danzberger, N.; Dietrich, P.; Sauer, N.; Stadler, R. Protoplast-esculin assay as a new method to assay plant sucrose transporters: Characterization of AtSUC6 and AtSUC7 sucrose uptake activity in Arabidopsis Col-0 ecotype. Front. Plant. Sci. 2018, 9, 430-451. [CrossRef]

30. Riesmeier, J.W.; Hirner, B.; Frommer, W.B. Potato sucrose transporter expression in minor veins indicates a role in phloem loading. Plant. Cell 1993, 5, 1591-1598.

31. Boorer, K.J.; Loo, D.D.; Frommer, W.B.; Wright, E.M. Transport mechanism of the cloned potato H+/sucrose cotransporter StSUT1. J. Biol. Chem. 1996, 271, 25139-25144. [CrossRef] [PubMed]

32. Haus, S.; Jabbari, S.; Millat, T.; Janssen, H.; Fischer, R.R.; Bahl, H.; King, J.R.; Wolkenhauer, O. A systems biology approach to investigate the effect of $\mathrm{pH}$-induced gene regulation on solvent production by Clostridium acetobutylicum in continuous culture. BMC Syst. Biol. 2011, 5, 10. [CrossRef] [PubMed]

33. Jiang, M.; Chen, J.N.; He, A.Y.; Wu, H.; Kong, X.P.; Liu, J.L.; Yin, C.Y.; Chen, W.F.; Chen, P. Enhanced acetone/butanol/ethanol production by Clostridium beijerinckii IB4 using $\mathrm{pH}$ control strategy. Process. Biochem. 2014, 49, 1238-1244. [CrossRef]

34. Malaviya, A.; Jang, Y.S.; Lee, S.Y. Continuous butanol production with reduced byproducts formation from glycerol by a hyper producing mutant of Clostridium pasteurianum. Appl. Microbiol. Biotechnol. 2012, 93, 1485-1494. [CrossRef] [PubMed]

35. Chen, C.K.; Blaschek, H.P. Effect of acetate on molecular and physiological aspects of Clostridium beijerinckii NCIMB 8052 solvent production and strain degeneration. Appl. Environ. Microb. 1999, 65, 499-505.

36. Girbal, L.; von Abendroth, G.; Winkler, M.; Benton, P.M.; Meynial-Salles, I.; Croux, C.; Peters, J.W.; Happe, T.; Soucaille, P. Homologous and heterologous overexpression in Clostridium acetobutylicum and characterization of purified clostridial and algal Fe-only hydrogenases with high specific activities. Appl. Environ. Microb. 2005, 71, 2777-2781. [CrossRef]

37. Mermelstein, L.D.; Papoutsakis, E.T. In vivo methylation in Escherichia coli by the Bacillus subtilis phage phi 3T I methyltransferase to protect plasmids from restriction upon transformation of Clostridium acetobutylicum ATCC 824. Appl. Environ. Microb. 1993, 59, 1077-1081.

38. Tummala, S.B.; Welker, N.E.; Papoutsakis, E.T. Design of antisense RNA constructs for downregulation of the acetone formation pathway of Clostridium acetobutylicum. J. Bacteriol. 2003, 185, 1923-1934. [CrossRef]

39. Mermelstein, L.D.; Welker, N.E.; Bennett, G.N.; Papoutsakis, E.T. Expression of cloned homologous fermentative genes in Clostridium acetobutylicum ATCC 824. Bio/Technology 1992, 10, 190-195. [CrossRef]

Sample Availability: Samples of the microbial strains are available from the authors. 